\title{
Uveal involvement in Marburg virus disease
}

\author{
B. S. KUMING AND N. KOKORIS \\ From the Department of Ophthalmology, Johannesburg General Hospital and University of the \\ Witwatersrand
}

SUMMARY The first reported case of uveal involvement in Marburg virus disease is described. 'Ex Africa semper aliquid novi'.

Two outbreaks of Marburg virus disease have been documented. The first occurred in Marburg and Frankfurt, West Germany, in 1967 (Martini, 1969) and the second in Johannesburg in 1975 (Gear, 1975). This case report describes the third patient in the Johannesburg outbreak, who developed an anterior uveitis. The cause of the uveitis was proved to be the Marburg virus by identiying it in a tissue culture of her aqueous fluid.

\section{Case report}

Before describing the case history of the patient the events leading to her contracting the disease must be briefly described. The full details of the 3 patients affected have already been reported (Gear, 1975).

A 20-year-old Australian man was admitted to hospital on 15 February 1975. He had just returned from Rhodesia when he developed myalgia, vomiting, high fever, and a mild lymphadenopathy. He also had intensely congested conjunctivae. There was a recent insect bite in the right flank. He had a pronounced leucopaenia but peripheral smears for malaria and trypanosomiasis were negative. He was diagnosed as suffering from typhoid fever and treated accordingly. He developed profuse bloodstained diarrhoea and vomiting and his renal function deteriorated rapidly. There was a maculopapular rash. Peripheral blood smears suggested a viral infection. Examination of his stools was negative for plague. Despite the most intensive therapy he died from hepatorenal failure 4 days after admission. $\mathrm{He}$ had a terminal disseminated intravascular coagulopathy.

Two days after his death his 20-year-old girl friend presented with similar initial complaints. She had accompanied him on his travels through

Address for reprints: Mr B. S. Kuming, 716 Tower Hill, Corner Kotze and Klein Streets, Hillbrow, Johannesburg 2001, South Africa
Rhodesia and had also been constantly at his bedside till his death. Lassa fever was suspected and she was given a unit of Lassa fever convalescent serum when she became desperately ill on the fifth day. She also developed acute pancreatitis. Within 52 hours she made a dramatic and uneventful recovery. Her illness mainly affected the haematopoietic, hepatic, and pancreatic systems.

The subject of this report was a nurse who had helped to nurse patients 1 and 2 . Nine days after the death of the first patient she presented with lower back pain and high fever. She developed hepatitis, a mild disseminated intravascular coagulation syndrome, successfully treated with heparin, and the classical rash for the disease. She also had injected conjunctivae.

She was given Lassa fever convalescent serum but did not respond within 48 hours. For the first time Marburg virus disease was suspected. On day 7 she spontaneously improved. She was discharged after 21 days, when the diagnosis of Marburg virus disease was confirmed.

Three months after her recovery she came to the eye department complaining of a painful right eye and blurred vision for the past 2 weeks. She was constitutionally well. Her visual acuity was right eye $6 / 7 \cdot 5$, left eye $6 / 6$. The left eye was normal in all respects. The right eye showed mild congestion of the conjunctiva, a + flare and ++ cells in the anterior chamber, and an intraocular pressure of $50 \mathrm{mmHg}$. The vitreous, disc, macula, and peripheral retina were all normal. The retina showed a number of small, yellowish-white drusen bodies. No vitreal reaction was seen over them and their appearance has remained unchanged since they were first observed. Fluorescein angiography was normal. Gonioscopy showed a normal angle. She was started on acetazolamide, atropine, and topical corticosteroids 2 hourly. The tension was rapidly controlled and diamox was stopped after 3 days. Subsequent daily measurements showed no increase of her 
tension. She developed white keratic precipitates in her right eye. A full uveitis battery was negative.

Seven days after her presentation her anterior chamber was still active and an aqueous tap was performed. Tissue culture of the aqueous yielded Marburg virus. Typical inclusion bodies were found in the cytoplasm of vero cells. The iritis slowly decreased and a repeat tissue culture of aqueous 2 weeks later was negative. Two months later and again in January 1976, she had further attacks of iritis. These both resolved rapidly without any untoward sequelae.

\section{Discussion}

Marburg disease is a pantropic acute febrile infection due to a highly pathogenic virus transmitted by vervet monkeys (Cercopithecus aethiops). It belongs to no taxonomonic group. It has an incubation period of 7 days. The differential diagnosis includes all haemorrhagic fevers such as yellow fever, plague, typhus, malaria, and Lassa fever. The clinical features of Marburg virus disease are very similar to Lassa fever, so named after the area of West Africa where it first occurred (Monath, 1974). Both diseases are characterised by high mortality and person-to-person transmission. Their importance in public health is obvious.

The diagnosis of Marburg virus disease was jointly made at the Centre for Disease Control, Atlanta, USA, and the Poliomyelitis Research Foundation, Johannesburg, South Africa. A fluores- cent antibody was also shown to develop in the sera of all 3 patients against the isolated Marburg virus.

This is the first reported case of Marburg fever as a cause of uveitis. The diagnosis was proved by tissue culture of aqueous. Since this was positive while the patient had raised serum antibody levels we may assume that the antibody had not neutralised live virus in the uveal tract cells. This point was particularly important as the patient was about to start an obstetric course. Nevertheless, cultures of stool, urine, and throat swabs were negative, and when culture of aqueous from the second tap was found to be negative she was allowed to start work. Interestingly, one of the patients in the 1967 outbreak had circulating antibodies and yet transmitted the disease venereally. Live virus was isolated from his semen.

The disease was thought at first to be endemic for Uganda and Kenya, but this is obviously incorrect. It now extends down to Rhodesia and possibly the Republic of South Africa.

\section{References}

Gear, J. S. S., Cassel, G. A., Gear, A. J., Trappler, B., Clausen, I., Meyers, A. M., Kew, M. C., Bothwell, T. B., Sher, R., Miller, G. B., Schneider, J., Koornhof, H. J., Gomperts, E. D., Isaäcson, M., and Gear, J. H. S. (1975). Outbreak of Marburg virus disease in Johannesburg, British Medical Journal, 4, 489.

Martini, G. A. (1969). Marburg agent disease. Transactions of the Royal Society of Tropical Medicine and Hygiene, 63, 295.

Monath, T. P. (1974). Lassa fever and Marburg virus disease. WHO Chronicle, 28, 212. 